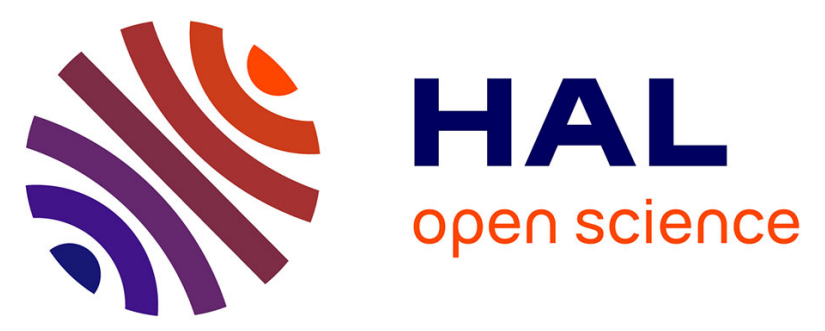

\title{
Design of a polypeptide FRET substrate that facilitates study of the antimicrobial protease lysostaphin
}

Philip Bardelang, Mireille Vankemmelbeke, Ying Zhang, Hannah Jarvis, Eleni Antoniadou, Sophie Rochette, Neil R Thomas, Christopher N Penfold, Richard James

\section{To cite this version:}

Philip Bardelang, Mireille Vankemmelbeke, Ying Zhang, Hannah Jarvis, Eleni Antoniadou, et al.. Design of a polypeptide FRET substrate that facilitates study of the antimicrobial protease lysostaphin. Biochemical Journal, 2009, 418 (3), pp.615-624. 10.1042/BJ20081765 . hal-00479093

\section{HAL Id: hal-00479093 https://hal.science/hal-00479093}

Submitted on 30 Apr 2010

HAL is a multi-disciplinary open access archive for the deposit and dissemination of scientific research documents, whether they are published or not. The documents may come from teaching and research institutions in France or abroad, or from public or private research centers.
L'archive ouverte pluridisciplinaire HAL, est destinée au dépôt et à la diffusion de documents scientifiques de niveau recherche, publiés ou non, émanant des établissements d'enseignement et de recherche français ou étrangers, des laboratoires publics ou privés. 


\section{Design of a polypeptide FRET substrate that facilitates study of the antimicrobial protease lysostaphin}

Philip BARDELANG*, Mireille VANKEMMELBEKE*, Ying ZHANG*, Hannah JARVIS*, Eleni ANTONIADOU
Richard JAMES $^{*}$, Sophie ROCHETTE

Institute of Infection, Immunity and Inflammation, School of Molecular Medical Sciences, Centre for Biomolecular Sciences and ${ }^{\dagger}$ School of Chemistry, Centre for Biomolecular Sciences, University of Nottingham, University Park, Nottingham NG7 2RD, U.K

Short Title: FRET substrate for glycyl-glycine endopeptidase

Abbreviations used: FRET, fluorescence resonance energy transfer; S.aureus, Staphylococcus aureus; MV11, polypeptide lysostaphin substrate; MV11F, polypeptide lysostaphin FRET substrate

${ }^{1}$ To whom correspondence should be addressed (email richard.james@nottingham.ac.uk)

Professor Richard James

Institute of Infection, Immunity and Inflammation

School of Molecular Medical Sciences

Centre for Biomolecular Sciences

University of Nottingham

University Park

Nottingham NG7 2RD 


\section{SYNOPSIS}

We have developed a polypeptide FRET substrate (MV11F) for the endopeptidase activity of lysostaphin. Site-directed mutants of lysostaphin that abolished the killing activity against Staphylococcus aureus also completely inhibited the endopeptidase activity against the MV11 FRET substrate. Lysostaphin-producing staphylococci are resistant to killing by lysostaphin through incorporation of serine residues at position 3 and 5 of the pentaglycine cross-bridge in their cell walls. The MV11 FRET substrate was engineered to introduce a serine residue in turn at four positions of the pentaglycine target site and revealed that only a serine residue at position 3 completely inhibited cleavage. The introduction of random, natural amino acid substitutions at position 3 of the pentaglycine target site demonstrated that only a glycine residue at this position was compatible with lysostaphin cleavage of the MV11 FRET substrate. A second series of polypeptide substrates (decoys) was developed with the GFP domain of MV11 replaced with that of the DNase domain of colicin E9. Using a competition FRET assay the lysostaphin endopeptidase was shown to bind to a decoy peptide containing a GGSGG cleavage site. The MV11 substrate provides a valuable system to facilitate structure/function studies of the endopeptidase activity of lysostaphin and its orthologues.

Keywords: colicin E9, endopeptidase, FRET assay, lysostaphin, LytM, Staphylococcus aureus, 


\section{INTRODUCTION}

Lysostaphin is an antimicrobial protease, that is often incorrectly termed a peptide, produced by Staphylococcus simulans biovar staphylolyticus that is active against S.aureus strains [1]. It is encoded by the pACK1 plasmid [2] and is synthesized as a 493 residue pre-proenzyme that consists of a 36 residue signal peptide, fifteen tandem repeats of 13 amino acids, fourteen of which have the identical sequence AEVETSKAPVENT. Removal of the signal peptide and the tandem repeats results in the mature enzyme of 247 amino-acids [3] that consists of an $N$-terminal 132 residue catalytic domain, followed by a thirteen residue linker which is attached to the 102 residue targeting domain. The signal peptide is cleaved during protein export from the bacterial cytoplasm, and the fifteen tandem repeats are removed by a cysteine protease that is also secreted into the culture medium [2]. It has been demonstrated that the target specificity of the mature lysostaphin is mediated by a 92 residue $C$-terminal targeting domain that is also required for rapid processing of the proenzyme form of lysostaphin to the mature form [4]. Lysostaphin is a member of the M37/M23 zinc endopeptidase family that cleaves the pentaglycine cross-bridges [5] that are found in the cell wall of S.aureus, S.simulans and S.carnosus [6]. It has been suggested that lysostaphin cleaves specifically between the third and fourth glycine residues of the pentaglycine cross-bridge based on the release of staphylococcal surface proteins by lysostaphin [7]. However analysis of lysostaphin cleaved muropeptides by mass spectrometry revealed that cleavage occurs between glycine residues 2 and 3, 3 and 4 and 4 and 5, with a preference for the latter cleavage site [8].

The potential therapeutic use of lysostaphin has been investigated in several animal models [9, 10]. Despite encouraging results, lysostaphin was not developed for clinical use due to (a) the difficulty of producing large amounts of pure preparations of lysostaphin; (b) the availability of other effective antibiotics; and (c) possible concern over the potential immunogenicity of the protease [11]. The continued rise in the problem of multiple antibiotic resistance in pathogenic bacteria, especially in methicillin resistant S.aureus (MRSA) isolates has led to the search for alternative therapeutic agents and renewed interest in lysostaphin [11-14], especially as it disrupts biofilms of S.aureus [15] that are normally difficult to treat with antibiotics. Lysostaphin-coated catheters have also been shown to prevent catheter colonization by several strains of S.aureus, and activity was maintained for at least 4 days [16]. Transgenic cows secreting lysostaphin in their milk were shown to be protected against $S$. aureus mastitis, which is responsible for up to $30 \%$ of mastitis infection in cattle at a cost of $\$ 600$ million annually in 2005 [17].

Despite almost 40 years of research on lysostaphin there are still considerable gaps in our knowledge of how lysostaphin targets S.aureus cells and then cleaves the pentaglycine crossbridge. Information on the nature of the lysostaphin receptor in S.aureus cells has only recently been revealed [18], and there are no reported mutants in lysostaphin that inactivate its biological activity. Other glycyl-glycine endopeptidase orthologues of lysostaphin have been reported including ALE-1 from Staphylococcus capitis EPK1 that is $83 \%$ identical to the mature lysostaphin sequence [19] and LytM from Staphylococcus aureus [20] where residues 185-315 are $49 \%$ identical to the endopeptidase domain of lysostaphin (residues 8-138). The existence of other members of this M37/M23 protease family such as zoocin A in Streptococcus equi subsp. zooepidemicus 4881 [21], enterolysin A in Enterococcus faecalis DPC5280 [22], and millericin B in Streptococcus milleri NMSCC 061 [23], produced by host organisms that do not contain pentaglycine cross-bridges in their cell walls, implies a wealth of structure/function information and novel antimicrobial agents that could be revealed by a comparative study of this group of endopeptidases.

The published assays of endopeptidase activity of lysostaphin are not sufficiently adaptable for structure/function studies of this family of endopeptidases [24-26]. We recently described the design and synthesis of three internally quenched substrates for lysostaphin based upon the peptidoglycan crossbridge of S.aureus and their use in FRET assays [27]. In this paper we describe the development of a novel polypeptide FRET substrate (MV11F) that facilitates the analysis of the endopeptidase activity of lysostaphin and LytM. We have validated the FRET assay by demonstrating that site-directed mutants that abolish the biological activity of lysostaphin similarly inhibit the endopeptidase activity against the FRET substrate. We have also identified the site of lysostaphin cleavage of the pentaglycine target sequence in the polypeptide FRET substrate and generated new information on the affect of serine residues in the pentaglycine 
target sequence on cleavage. Our long term aim is to solve the structure of lysostaphin and its homologues bound to a non-cleavable peptide/peptidomimetic and to use the structural information to help design novel antibiotics with an extended spectrum of activity against Gram positive pathogens.

\section{MATERIALS AND METHODS}

\section{Materials}

E.coli DH5 $\alpha$ (Novagen) was used as the host for cloning and mutagenesis. E.coli BL21 (DE3) and ER2566 (NEB) were used as host strains for the expression vector pET21a (Novagen). E.coli were grown at $37^{\circ} \mathrm{C}$ in Luria-Bertani or 2YT media [28] with ampicillin added $\left(100 \mu \mathrm{g} \mathrm{m}{ }^{-1}\right)$ for selection of resistant cells. Plasmid pGFPuv (Clontech) was the source of the GFPuv sequence. Alexa Fluor $546-\mathrm{C}_{5}$-maleimide was obtained from Invitrogen, UK.

\section{Cloning of lysostaphin and its endopeptidase domain}

Although lysostaphin has been cloned previously by several groups [2, 29], we engineered a $C$ terminal hexahistidine tag in order to facilitate the purification and analysis of mutant proteins. Using PCR with Staphylococcus simulans biovar staphylolyticus template DNA, we introduced a methionine codon immediately upstream of the first alanine codon of mature lysostaphin (primer RJ84), and an XhoI site, and thus two additional amino acids (LE), in place of the stop codon of the lysostaphin gene (primer DW41) [2]. The resulting $747 \mathrm{bp}$ PCR product was restricted with NdeI and XhoI and then ligated into expression vector pET21a restricted with the same enzymes, resulting in plasmid pEA3.

The cloning and expression of the isolated endopeptidase domain of lysostaphin has not been reported previously. The endopeptidase domain of lysostaphin was amplified by PCR from plasmid pEA3 using primer RJ84 and primer PTB7 that inserts an XhoI site in place of the Y141 codon of the lysostaphin gene, and cloned into pET21a restricted with NdeI and XhoI, resulting in plasmid pPTB201. The cloning of the endopeptidase domain of the lysostaphin orthologue Zoocin A has recently been reported [30].

\section{Cloning of S.aureus LytM and the active truncation LytM A185-316}

S.aureus RN450 genomic DNA was the template in a PCR using primers RJ81 (inserts an NcoI site, and thus a methionine codon, in place of the serine 25 codon of LytM) and PTB63 (inserts an XhoI site, and thus two additional amino acids (LE), in place of the stop codon of the lytM gene). The resulting $882 \mathrm{bp}$ PCR product was restricted with $N$ coI and XhoI and then ligated into similarly restricted pET21d. resulting inplasmid pPTB105. The cloning and expression of an active isolated endopeptidase domain of LytM was reported previously [26]. This endopeptidase was amplified by PCR from plasmid pPTB105 using primers PTB66 ( NcoI site in place of the histidine 184 codon of the lytM gene) and PTB63 (replaces the stop codon with and XhoI site as above). The resulting PCR product was restricted with NcoI and XhoI, ligated into similarly restricted pET21d, resulting in plasmid pPTB107.

\section{Construction of the FRET substrate}

A DNA fragment encoding the $N$-terminal 57 amino acids of colicin E9 was amplified from plasmid pNP69 [31], using primers T7 promoter and MV14 (introduced N44C and S50G mutations and an XmaI site at the 3' end of the PCR product). This PCR product was then subcloned into the cloning vector pET21a already containing the GFPuv sequence followed by a $C$ terminal hexahistidine tag. A cysteine residue was introduced by a N44C mutation and allowed labelling of the encoded protein MV11 with Alexa Fluor $546-\mathrm{C}_{5}$-maleimide and thus resulted in a biological FRET substrate, MV11F.

\section{Site-directed mutants}

Site-directed mutants of the mature lysostaphin gene were constructed from pEA3 using the "megaprimer" PCR method [32]. 


\begin{abstract}
Biological activity assays
Lysostaphin-producing E.coli ER2566 (DE3) cultures were stabbed into LB agar plates containing ampicillin $\left(100 \mu \mathrm{g} \mathrm{ml}^{-1}\right)$ and were incubated at $37^{\circ} \mathrm{C}$ overnight. The plates were exposed to chloroform vapour for $15 \mathrm{~min}$ to lyse the cells and were then overlaid with $5 \mathrm{ml}$ molten $0.7 \%$ $(\mathrm{w} / \mathrm{v})$ non-nutrient agar containing $50 \mu \mathrm{l}$ of an overnight culture of the MRSA indicator strain. The plates were incubated at $37^{\circ} \mathrm{C}$ for at least $6 \mathrm{~h}$ and then inspected for a clear zone of growth inhibition around the test culture. Each culture was tested independently in triplicate.
\end{abstract}

\title{
Metal-chelate chromatography
}

Protein expression was induced by IPTG $(1 \mathrm{mM})$ in cultures of E.coli BL21 (DE3) carrying the relevant plasmid growing in $2 \mathrm{YT}$-ampicillin $\left(100 \mu \mathrm{g} \mathrm{ml}^{-1}\right)$ media at $25^{\circ} \mathrm{C}$. Initial purifications of lysostaphin and its endopeptidase using nickel-affinity chromatography yielded proteins with reduced biological (and catalytic) activity when compared with zinc purified proteins [27]. For zinc-affinity chromatography frozen cells were gently resuspended in buffer $(20 \mathrm{mM}$ Tris-HCl $\mathrm{pH}$ 7.0, $0.5 \mathrm{M} \mathrm{NaCl}, 5 \%$ (v/v) glycerol) with $1 \mathrm{mM} \mathrm{PMSF}$, sonicated on ice then subject to centrifugation. The cleared cell lysate was applied to a $5 \mathrm{ml}$ HiTRAP chelate column (Pharmacia Biotech, UK) previously charged with zinc and equilibrated in buffer. Bound proteins were eluted from the column using a linear gradient of increasing imidazole. Fractions containing the required protein, identified by SDS-PAGE, were pooled and dialysed overnight $\left(4^{\circ} \mathrm{C}\right)$ in the appropriate buffer for ion-exchange chromatography.

His-tagged lysostaphin(s), and the lysostaphin endopeptidase domain were diluted 10-fold into buffer cexA $(10 \mathrm{mM}$ Tris $\mathrm{pH} 7.0,50 \mathrm{mM} \mathrm{NaCl}, 5 \%(\mathrm{v} / \mathrm{v})$ glycerol, $0.1 \%(\mathrm{v} / \mathrm{v})$ Triton-X100). Histagged biological substrates were diluted 3-fold in buffer aexA; $20 \mathrm{mM}$ Tris pH 8.1, $25 \mathrm{mM} \mathrm{NaCl}$, $5 \%(\mathrm{v} / \mathrm{v})$ glycerol, $1 \mathrm{mM}$ DTT. His-tagged LytM A185-316 was stored overnight $\left(4^{\circ} \mathrm{C}\right)$ without dialysis prior to cation-exchange chromatography.

\section{Cation-exchange chromatography}

Lysostaphin or endopeptidase domain in buffer cexA was loaded on to a $5 \mathrm{ml}$ HiTRAP SP column equilibrated in buffer cexA then eluted using a linear gradient of increasing sodium chloride. Fractions containing only the required protein were identified using SDS-PAGE and stored at $80 \mathrm{oC}$. His-tagged LytM A185-316 was purified using a $5 \mathrm{ml}$ HiTRAP DEAE FF column as previously described [26]. The flowthrough fraction contained purified LytM A185-316 which was concentrated using a Microcon Centriplus YM3 centrifugal filter device with a $3 \mathrm{kDa}$ cut-off and stored at $-80 \mathrm{oC}$.

\section{Anion-exchange chromatography of the biological substrates}

His-tagged biological substrate was loaded on a $1 \mathrm{ml}$ MonoQ column (Pharmacia Biotech, UK) equilibrated in buffer aexA and then eluted using a linear gradient of increasing sodium chloride. Fractions containing isolated biological substrate were identified using SDS-PAGE and stored at $80 \mathrm{oC}$.

To obtain purified decoy peptide from E.coli cell lysates that have expressed decoy:colicin E9 immunity complexes we used zinc-affinity chromatography to capture the complex and a denaturing elution buffer to isolate the decoy peptide from the immobilized immunity protein. E.coli cell lysates were loaded onto a $5 \mathrm{ml}$ HiTRAP chelate column as described for the MV11 biological substrates, washed in buffer $\mathrm{A}$, and then eluted in $20 \mathrm{mM}$ Tris- $\mathrm{HCl} \mathrm{pH} \mathrm{7.9,6} \mathrm{M}$ guanidine, $0.5 \mathrm{M} \mathrm{NaCl}$. Decoy substrates were dialysed in $100 \mathrm{mM}$ ammonium bicarbonate $\mathrm{pH}$ 7.8 and lyophilized to allow mass spectrometry and enable resuspension in FRET buffer at high concentration.

\section{Protein concentration determinations}

The concentration of all purified proteins were determined by UV absorbance at $280 \mathrm{~nm}$. The following extinction coefficients were determined online by the Expert Protein Analysis System (ExPASy) tool Protpram [33], using the amino acid sequence of each protein; lysostaphin and mutants, $67840 \mathrm{M}^{-1} \mathrm{~cm}^{-1}$; the endopeptidase domain, $36900 \mathrm{M}^{-1} \mathrm{~cm}^{-1}$; LytM $63720 \mathrm{M}^{-1} \mathrm{~cm}^{-1}$; LytM A185-316, $32890 \mathrm{M}^{-1} \mathrm{~cm}^{-1}$; decoy substrates $31970 \mathrm{M}^{-1} \mathrm{~cm}^{-1}$. The concentration of the biological substrates was determined using the absorbance of GFP at $397 \mathrm{~nm}$ and an extinction coefficient of $30,000 \mathrm{M}^{-1} \mathrm{~cm}^{-1}$ (Clontech). 


\section{Turbidity assay}

A turbidity assay, similar to that previously described [34] was used to demonstrate lysostaphin activity, in which lyophilised EMRSA-16 cells [35] were resuspended in buffer (25 mM sodiumphosphate $\mathrm{pH} 7.0,171 \mathrm{mM} \mathrm{NaCl}$ ) and the $\mathrm{OD}_{600}$ monitored continuously using a Shimadzu $160 \mathrm{~A}$ spectrophotometer or Wallac Victor ${ }^{2}$ mutlilabel counter at ambient temperature. After $\sim 5$ min, lysostaphin $\left(5 \mu \mathrm{M}\right.$ final concentration) was added and changes in $\mathrm{OD}_{600}$ observed. To show that a lysostaphin mutant protein retained the ability to bind S.aureus, the assay was repeated with the mutant lysostaphin $(10 \mu \mathrm{M}$ final concentration) mixed with lysostaphin.

\section{Polypeptide cleavage assay}

To assess the cleavage of solvent exposed "pentaglycine" amino acid sequences by lysostaphin each of the MV11 family of biological substrates ( $20 \mu \mathrm{M}$ final concentration) were incubated with lysostaphin $\left(2 \mu \mathrm{M}\right.$ final concentration) for $4 \mathrm{~h}$ at $37^{\circ} \mathrm{C}$ in buffer $(25 \mathrm{mM}$ sodium-phosphate $\mathrm{pH}$ $7.0,150 \mathrm{mM} \mathrm{NaCl}$ ). Digests were stopped with the addition of an equal volume of SDS-PAGE loading buffer and cleavage assessed by SDS-PAGE.

\section{Fluorescence}

Fluorescence measurements were acquired at $37^{\circ} \mathrm{C}$ using a LS55B luminescence spectrometer fitted with a thermostatted cell holder (Perkin Elmer) operating FLWinlab ${ }^{\circledR}$ software.

\section{Labelling of the polypeptide FRET substrate}

Polypeptide FRET substrates were labelled with a 15-fold molar excess of Alexa Fluor $546-\mathrm{C}_{5^{-}}$ maleimide for $2 \mathrm{~h}$ at room temperature. Excess DTT was added and free label was removed by exhaustive dialysis of the substrates against PBS ( $\mathrm{pH} 7.4)$. Energy transfer diminishes rapidly with increasing distance between the donor and acceptor (FRET efficiency $\mathrm{E}=\mathrm{R}_{0}{ }^{6} /\left(\mathrm{R}_{0}{ }^{6}+\mathrm{r}^{6}\right)$ where $\mathrm{r}$ is the distance between the donor and acceptor and $R_{0}$ is the distance at which transfer efficiency is $50 \%$ of maximum) [36]. For the FRET substrate MV11F the $\mathrm{R}_{0}$ value is $51 \AA$ [37].

\section{Polypeptide FRET endopeptidase assay}

Cleavage of the MV11F substrates by lysostaphin was followed continuously over a five minute period by measuring the fluorescence yield at $\lambda_{508} \mathrm{~nm}$ (Em slit width of $10 \mathrm{~nm}$ ) that resulted from excitation at $\lambda_{475} \mathrm{~nm}$ (Ex slit width of $5 \mathrm{~nm}$ ). The substrate in $150 \mu 1$ of $25 \mathrm{mM}$ sodium-phosphate (pH 7.0), $150 \mathrm{mM} \mathrm{NaCl}$ buffer was added into a $1 \mathrm{~cm}$ path length cuvette and equilibrated at $37^{\circ} \mathrm{C}$ in the thermostatted cell compartment of the fluorimeter prior to the addition of lysostaphin.

\section{ESI - TOF mass spectrometry}

The masses of peptides were measured by ESI-TOF MS using a Micromass LCT operating the reflector in positive ion mode. The instrument was calibrated using equine heart myoglobin (Sigma). Peptides were dialysed extensively in $100 \mathrm{mM}$ ammonium bicarbonate buffer $\mathrm{pH} 7.8$ $\left(4^{\circ} \mathrm{C}\right)$, lyophilized and then dissolved in $50 \%(\mathrm{v} / \mathrm{v})$ acetonitrile, $\sim 1 \%$ formic acid for application into the spectrometer. Peptide digestions were performed in $100 \mathrm{mM}$ ammonium bicarbonate buffer $\mathrm{pH} 7.8\left(37^{\circ} \mathrm{C}\right)$ using the minimum enzyme necessary and for up to $36 \mathrm{~h}$. The multiplycharged ion data was transformed into a singly charged ion indicative of the molecular weight using a custom software package.

\section{RESULTS}

\section{Expression and purification of lysostaphin, endopeptidase and mutant proteins}

Mature, recombinant lysostaphin, consisting of residues 247-493 [2], was purified from an IPTG induced culture of E.coli BL21 [DE3] pEA3 by zinc metal chelate chromatography, making use of the introduced $C$-terminal hexa-histidine tag, followed by cation-exchange chromatography. Similarly the isolated endopeptidase domain of lysostaphin, consisting of residues 1-140 was purified from an E.coli BL21 [DE3] pPTB201 culture. ESI-TOF Mass spectrometry analysis of the purified proteins gave a molecular weight of 28,012.8 Da for lysostaphin and 16,256.3 Da for the endopeptidase domain, compared with the predicted values of 28,008.4 $\mathrm{Da}$ and 16,254.1 Da respectively for the two proteins missing their $N$-terminal methionine residues. 
In order to validate our lysostaphin assays we constructed some endopeptidase mutants of lysostaphin. Blast searches (www.ncbi.nlm.nih.gov/BLAST/) using the endopeptidase domain of lysostaphin reveal similar sequences in a large number of Gram-positive and Gram-negative bacteria, which on alignment revealed seven residues, other than glycines, that are absolutely conserved (Figure 1A). We used alanine scanning mutagenesis to investigate the effect of mutating all seven of these residues (H33, D37, Y81, H83, T107, H114 and H116) of the mature lysostaphin sequence encoded by plasmid pEA3 on the biological activity. The results clearly showed that mutagenesis of H33, D37, H83, H114, or H116 to alanine abolished the biological activity of the mutant lysostaphin in the stab test, whilst mutations of Y81 or T107 to alanine resulted in a reduced killing zone size (Figure 1B). The seven mutant proteins were then assayed in a turbidity assay, in comparison to the mature lysostaphin (Figure 1C). To exclude the possibility that the five alanine mutations inactivated the endopeptidase activity by destabilizing the conformation of the mutant lysostaphin proteins, we demonstrated that the mutant proteins were able to protect S.aureus cells from killing by mature lysostaphin in a turbidity protection assay (data not shown), thus showing that the mutant proteins retained normal S.aureus targeting activity and thus the $C$-terminal targeting domain at least must be normally folded.

\section{A polypeptide FRET substrate for the glycyl-glycine endopeptidase activity}

We recently described the design and synthesis of three internally quenched peptide FRET substrates for lysostaphin [27]. The relatively low binding affinity of lysostaphin for the three FRET substrates $\left(\mathrm{K}_{\mathrm{m}}\right.$ values of between 0.7 and $\left.3 \mathrm{mM}\right)$ required that they be used at relatively high substrate concentrations, with resulting solubility problems, and in the presence of high concentrations of enzyme. For this reason we explored alternative polypeptide FRET substrates that might exhibit a higher sensitivity and would also be amenable to protein engineering and thus allow a range of mutant substrates to be rapidly produced. The polypeptide FRET substrate was based upon the $N$-terminal region of the translocation domain of colicin E9 as this is known to be a natively disordered region (NDR) of the protein [38] and thus an introduced pentaglycine cleavage site might be readily accessible to cleavage by the endopeptidase. We engineered a chimeric protein that consisted of the $N$-terminal 57 residues of colicin E9, a seven residue linker and the GFPuv protein, with a $C$-terminal hexa-histidine tag to facilitate protein purification. The amino-acid sequence of the $N$-terminal 64 residues that are linked to GFPuv is shown in Figure 2. The mutation S50G created a pentaglycine cleavage site between residues 47-51, whilst the S52A and G53A mutations removed a possible extension of the endopeptidase cleavage site. The cysteine residue that was introduced by a N44C mutation allowed labelling of MV11 with Alexa Fluor $546-\mathrm{C}_{5}$-maleimide to produce the polypeptide FRET substrate, MV11F.

Cleavage of both the MV11 or MV11F substrates could be observed by SDS-PAGE and demonstrated that labelling MV11 with Alexa Fluor $546-\mathrm{C}_{5}$-maleimide did not inhibit cleavage by lysostaphin or the endopeptidase domain (Figure 2). Mass spectrometry analysis of purified MV11 revealed a major species with a molecular weight of 33,681.2, which is consistent with the predicted molecular weight of MV11 without the $N$-terminal methionine residue of 33,680.9 Da. After cleavage by the endopeptidase domain, the large $C$-terminal fragment of MV11 was determined to be 29,445.5 Da (Table 1). Assuming cleavage between the second and third glycine residues of the pentaglycine target sequence of MV11, the predicted molecular weight of the large, $C$-terminal fragment that includes GFPuv is 29,442.7 Da. If cleavage occurred between the third and fourth, or the fourth and fifth glycine residues, then the predicted molecular weight of the large fragment is 29,386.1 Da and 29,329 Da respectively. The observed cleavage site between glycine residues 2 and 3 of the pentaglycine target sequence of MV11 is consistent with one of the three proposed cleavage sites identified by mass spectrometry of muropeptides after cleavage of S.aureus peptidoglycan with lysostaphin [8], and with the favoured cleavage site of lysostaphin in the synthetic FRET substrates [27].

Alexa Fluor 546 has an excitation maximum at 554nm and an emission maximum at 570nm. With excitation at $475 \mathrm{~nm}$, FRET will occur between the GFPuv and Alexa Fluor546 in MV11F such that the direct emission of GFPuv at $508 \mathrm{~nm}$ will decrease [37]. This is shown in Figure 3A. The FRET efficiency, E, can be calculated from the equation $\mathrm{E}=1-\mathrm{I}_{\mathrm{DA}} / \mathrm{I}_{\mathrm{D}}$ where $\mathrm{I}_{\mathrm{DA}}$ is the intensity of the donor in the presence of the acceptor (MV11F) and $I_{D}$ is the intensity of the donor alone (MV11), and in this case E 96\%. Incubation of the polypeptide FRET substrate MV11F with lysostaphin or the endopeptidase domain results in an increase in the emission at $508 \mathrm{~nm}$, 
reflecting the cleavage of the pentaglycine target sequence and thus separation of the FRET donor and FRET acceptor, with the rate of increase being linear over a five minute period (Figure 3B). Cleavage rates during the first two minutes for $200 \mathrm{nM}$ of enzyme and a range of MV11F concentrations $(0-20 \mu \mathrm{M})$ were obtained (data not shown). The rates were converted from relative fluorescence units to concentrations using a calibration curve of the fluorescence of known concentrations of GFPuv (MV11) and corrected for quenching effects at higher substrate concentrations [39]. Approximate kinetic constants were obtained by fitting the corrected rates to a Michaelis-Menten plot. The apparent $\mathrm{K}_{\mathrm{m}}$ was $65 \pm 27 \mu \mathrm{M}$ for lysostaphin and $92 \pm 41 \mu \mathrm{M}$ for the endopeptidase domain. The $V_{\max }$ was $10.1 \pm 3.5 \mathrm{nM} / \mathrm{s}$ for lysostaphin and $5.2 \pm 2.1 \mathrm{nM} / \mathrm{s}$ for the endopeptidase domain. The narrow substrate concentration range that could be used for analysis, due to fluorescence quenching effects at higher substrate concentrations, resulted in rather large standard errors for the fitting. The increased sensitivity of this assay, reflected in shorter incubation times when compared with the chemical FRET assay, was consistent with the $\mathrm{K}_{\mathrm{m}}$ values obtained in the latter assay of between $70 \mu \mathrm{M}$ and $200 \mu \mathrm{M}$ for the three chemical substrates [27].

\section{Cleavage of MV11 by other M37 endopeptidases}

Zoocin A is produced by Streptococcus equi subsp. zooepidemicus 4881 and is reported to have inhibitory activity against Streptococcus pyogenes and Streptococcus mutans [21]. The $N$-terminal endopeptidase domain of Zoocin A shows considerable homology to the endopeptidase domain of lysostaphin (Figure 1A) and surprisingly has been reported to cleave a hexaglycine substrate in a colorimetric assay even though the peptidoglycan cross-link in the sensitive Streptococcal strains is reported to consist of two or three L-alanine residues [40]. We observed no cleavage of MV11 by high concentrations of purified Zoocin A even though the protein showed the expected inhibitory activity against cultures of Streptococcus pyogenes (data not shown). LytM is an autolysin of S.aureus and is the first member of the group of lysostaphin metallopeptidases whose structure has been determined [26, 41]. We engineered a truncated LytM from Staphylococcus aureus, consisting of residues 185-316, and experimentally determined its mass as 15,277.6 compared with the predicted value of $15,274.0$ for the protein lacking its $N$-terminal methionine. The truncated LytM protein cleaved MV11 with an experimentally determined mass for the large $C$-terminal cleavage product of 29,327.1 (Table 1). This indicates that, in contrast to lysostaphin, cleavage of the MV11 substrate by LytM occurs between glycine residues 4 and 5 of the pentaglycine target sequence.

\section{Effect of serine residues on the cleavage of MV11 by lysostaphin and LytM}

Lysostaphin producing S.simulans strains are protected from killing by the production of a lysostaphin immunity factor (Lif) that is homologous to the FemA and FemB proteins that are essential for the synthesis of pentaglycine cross-bridges in S.aureus [3]. The presence of the Lif protein results in the incorporation of serine residues at positions 3 and 5 of the pentaglycine cross-bridge that prevent endopeptidase cleavage by lysostaphin [42-44], but it is not known if the incorporation of one or both serine residues is required. Using site-directed mutagenesis, we engineered the pMV11 plasmid to produce four constructs which encode MV11 proteins containing a serine residue at position 1,2,3 and 5 respectively of the pentaglycine cleavage site. We compared the cleavage of MV11 and the four serine-containing MV11 mutant proteins by lysostaphin using SDS-PAGE (Figure 4). The results demonstrated that a serine in the third position of the pentaglycine cleavage site (MV11-S3) abolished cleavage by lysostaphin or the endopeptidase, whilst the presence of a serine mutation at position one (MV11-S1), two (MV11S2), or five (MV11-S5) was observed to only decrease the rate of cleavage after long incubation times (Fig 4). Mass spectrometry analysis of the cleavage products of these long incubations confirmed the absence of cleavage of the MV11-S3 protein and that cleavage of MV11-S1, MV11-S2 and MV11-S5 by lysostaphin occurs between glycine residues 3 and 4, 4 and 5, and 2 and 3 respectively (Table 1 ).

The truncated LytM polypeptide cleaved MV11, MV11-S1 and MV11-S2 less efficiently than lysostaphin whilst cleavage of MV11-S5 was very efficient despite the preferential cleavage site being between glycine residues 4 and 5 (Table 1). Mass spectrometry analysis of the cleavage products of these long incubations confirmed the absence of cleavage of the MV11-S3 protein and that cleavage of MV11-S1 and MV11-S2 occurred between glycine residues 4 and 5. Cleavage of 
the MV11-S5 protein occurred between glycine residues 2 and 3 (Table 1). As expected, purified MV11-S3 labeled with Alexa Fluor546 (MV11-S3F) showed no cleavage when incubated with LytM (data not shown).

\section{Other residues at position 3 inhibit cleavage of the MV11 pentaglycine substrate}

In order to determine if other amino acid residues at position 3 of the pentagycine cleavage site in MV11 could inhibit cleavage by lysostaphin we engineered a stop codon at this position in MV11, resulting in the loss of fluorescence from the expressed protein. Using a mutagenic primer that randomly mutated the stop codon to a codon for any amino acid, we screened for transformants in which GFP fluorescence was restored. This can only result from the replacement of the stop codon with an amino-acid encoding codon, thus allowing expression of a full-size MV11 polypeptide. Rapid screening of cell lysates from these transformants, after incubating with the endopeptidase domain $(20 \mu \mathrm{M})$ and then running the digests on 16\% SDS-PAGE, indicated that eight of twenty five transformants expressed an MV11 biological substrate that could be cleaved by the endopeptidase. DNA sequencing revealed that a glycine residue had been introduced in place of the stop codon in these eight clones in which the MV11 mutant protein could be cleaved. The other seventeen clones had amino acids other than glycine present at this position including asparagine (in 3 clones), alanine (2), leucine (2), phenylalanine (2), valine, serine, threonine, cysteine and tryptophan. The MV11 substrate with an alanine residue at position 3 was purified and incubated with lysostaphin or LytM in buffer, rather than in the presence of LB media in the cell digest incubations, before running the digest on SDS-PAGE. The results showed that both lysostaphin and LytM can cleave this substrate after long incubations, which suggests that the presence of an alanine residue at this position does not prevent binding of these enzymes to the modified substrate. However purified MV11 substrates having valine or leucine in position 3 were not cleaved by lysostaphin or LytM in buffer. These experiments show the value of the MV11 substrate for studying the substrate preference of M37 endopeptidases like lysostaphin and LytM.

\section{A serine in the third position of the pentaglycine cleavage site does not prevent binding of the lysostaphin endopeptidase}

One of our long term aims is to solve the structure of lysostaphin bound to a non-cleavable peptide/peptidomimetic because this would enable rational mutagenesis of lysostaphin for the generation of new enzymes which cleave GGSGG sequences present in bacteria resistant to lysostaphin. To assess lysostaphin binding of MV11-S3 we performed a competition polypeptide FRET assay between fluorescently labelled MV11F and an unlabelled decoy peptide with a solvent exposed GGSGG cleavage site. The decoy peptide was engineered by substitution of the GFPuv encoding region of the MV11-3 substrate with the DNase-Im9 immunity protein encoding region from colicin E9 [45]. Further mutagenesis of the cleavage site resulted in two additional decoy peptides; a positive control peptide with a GGGGG site and a negative control peptide with an AASAA cleavage site. ESI-TOF Mass spectrometry analysis of the purified decoys gave a molecular weight of 20,654.7 Da for the decoy with the GGSGG cleavage site, 20,613.7 Da for the decoy with the GGGGG cleavage site and 20701.8 Da for the decoy with AASAA cleavage site, compared with the predicted values of 20643.7 Da, 20613.7 Da and 20699.8 Da respectively for the three proteins missing their $N$-terminal methionine residues. As expected incubation of each of the decoy substrates alone with lysostaphin or its endopeptidase only led to cleavage of the decoy with the GGGGG cleavage site (data not shown).

The different masses of MV11 and the decoy substrate allowed observation on SDS-PAGE of MV11 cleavage by lysostaphin when co-incubated with each of the decoy substrates. Cleavage of MV11F by the endopeptidase domain in the presence of excess of the GGSGG decoy was significantly reduced relative to cleavage of MV11F on its own, and similar to cleavage of MV11F in the presence of an equivalent excess of the decoy with the GGGGG cleavage site (Figure 5). Evidence for specific inhibition of endopeptidase cleavage by the above two decoy substrates was concluded from the finding that cleavage of MV11F in the presence of an equivalent excess of the AASAA decoy was not reduced. Inhibition of cleavage from the decoys with the GGGGG or GGSGG cleavage site was approximately forty fold greater than product inhibition of the endopeptidase by triglycine.

\section{DISCUSSION}


We have developed an assay for the endopeptidase activity of mature lysostaphin, or of its endopeptidase domain, that uses an engineered polypeptide substrate MV11. Cleavage of MV11 after long incubations with lysostaphin can be observed on SDS-PAGE gels but labeling of MV11 with Alexa Fluor 546 results in a sensitive FRET substrate (MV11F) in which cleavage by 200 $\mathrm{nM}$ lysostaphin can be observed during a 5 min assay period.

Clues as to the possible roles of the five essential residues that we have identified in our mutational studies in the endopeptidase activity of lysostaphin have come from the crystal structure of LytM [26, 41], and from mutational analysis of the glycyl-glycine endopeptidase ALE-1 [46]. The crystal structure shows that LytM is a two domain protein in which the $C$ terminal domain is conserved in lysostaphin metallopeptidases. Three zinc ligands were identified in this domain (H210, D214 and H293) that are conserved in lysostaphin homologues [26], and are equivalent to the H33, D37 and H116 residues (Figure 1A) that we have shown to be essential for endopeptidase activity (Figure 1B). The fourth zinc ligand in LytM is N117, which is located in the $N$-terminal domain of LytM and has no obvious equivalent in lysostaphin [26]. In ALE-1 alanine mutations of residues H150, D154, H200, H231 and $\mathrm{H} 233$ (that are equivalent to $\mathrm{H} 33$, D37, H83, H114 and H116 in lysostaphin) resulted in almost complete loss of enzymatic activity, whilst only the alanine mutations at $\mathrm{H} 150$ or $\mathrm{H} 233$ resulted in loss of a zinc molecule [46].

One other residue was shown to be essential for the biological activity of LytM, H291 which is equivalent to H114 in lysostaphin and H231 in ALE-1. This residue is at least $4 \AA$ away from the $\mathrm{Zn}^{2+}$ in the LytM crystal structure and thus not involved in metal chelation [26],. The precise role of this histidine residue in LytM, ALE-1 or lysostaphin, is currently unknown. One suggestion is that it could be acting as a General Base to activate the water molecule by deprotonating it and then a general acid to protonate the nitrogen of the amine leaving group, however it has been pointed out that residue $\mathrm{H} 260$ in LytM could also play this role [26]. It is significant that the H83 residue that we have demonstrated is essential for the biological activity of lysostaphin is equivalent to H260 residue of LytM. The crystal structure of the endopeptidase domain of lysostaphin, or LytM, in complex with a substrate analogue will be required to address this issue.

Resistance to lysostaphin is associated with the activity of the lif gene, that results in sitespecific incorporation of serine residues at position 3 and 5 of the pentaglycine cross-bridge of S.simulans [44]. Our data on the effect of site-specific serine residues on the cleavage of MV11 by lysostaphin, or the endopeptidase domain, strongly suggests that the incorporation of a serine at residue 3 in the pentaglycine will be a significant resistance factor in S.simulans if lysostaphin is used clinically. The first example of a plasmid encoded lif gene that is not associated with a closely linked endopeptidase gene has been reported in a Staphylococcus species [47] which suggests that this resistance gene could rapidly spread by horizontal gene transfer if lysostaphin is used clinically and justifies research to develop $2^{\text {nd }}$ generation lysostaphins that can cleave serine containing modified cleavage sites.

This project was funded by the University of Nottingham and The Wellcome Trust [066850/C/02/A]. We thank Graham Coxhill in the School of Chemistry, University of Nottingham for assistance with the mass spectrometry.

\section{REFERENCES}

1 Schindler, C. A. and Schuhardt, V. T. (1964) Lysostaphin: a New Bacteriolytic Agent for the Staphylococcus. Proc Natl Acad Sci U S A. 51, 414-421

2 Recsei, P. A., Gruss, A. D. and Novick, R. P. (1987) Cloning, sequence, and expression of the lysostaphin gene from Staphylococcus simulans. Proc Natl Acad Sci U S A. 84, 1127-1131

3 Thumm, G. and Gotz, F. (1997) Studies on prolysostaphin processing and characterization of the lysostaphin immunity factor (Lif) of Staphylococcus simulans biovar staphylolyticus. Mol Microbiol, 23, 1251-1265

4 Baba, T. and Schneewind, O. (1996) Target cell specificity of a bacteriocin molecule: a Cterminal signal directs lysostaphin to the cell wall of Staphylococcus aureus. Embo J. 15, $4789-4797$ 
5 Trayer, H. R. and Buckley, C. E. (1970) Molecular properties of lysostaphin, a bacteriolytic agent specific for Staphylococcus aureus. J Biol Chem. 245, 4842-4846

6 Schleifer, K. H. and Kandler, O. (1972) Peptidoglycan types of bacterial cell walls and their taxonomic implications. Bacteriol Rev. 36, 407-477

7 Schneewind, O., Fowler, A. and Faull, K. F. (1995) Structure of the cell wall anchor of surface proteins in Staphylococcus aureus. Science. 268, 103-106

$8 \mathrm{Xu}$, N., Huang, Z. H., de Jonge, B. L. and Gage, D. A. (1997) Structural characterization of peptidoglycan muropeptides by matrix- assisted laser desorption ionization mass spectrometry and postsource decay analysis. Anal Biochem. 248, 7-14

9 Climo, M. W., Patron, R. L., Goldstein, B. P. and Archer, G. L. (1998) Lysostaphin treatment of experimental methicillin-resistant Staphylococcus aureus aortic valve endocarditis. Antimicrob Agents Chemother. 42, 1355-1360

10 Dajcs, J. J., Hume, E. B., Moreau, J. M., Caballero, A. R., Cannon, B. M. and O_Callaghan, R. J. (2000) Lysostaphin treatment of methicillin-resistant Staphylococcus aureus keratitis in the rabbit. Invest Ophthalmol Vis Sci. 41, 1432-1437

11 Walsh, S., Shah, A. and Mond, J. (2003) Improved pharmacokinetics and reduced antibody reactivity of lysostaphin conjugated to polyethylene glycol. Antimicrob Agents Chemother. 47, 554-558

12 Climo, M. W., Ehlert, K. and Archer, G. L. (2001) Mechanism and suppression of lysostaphin resistance in oxacillin-resistant Staphylococcus aureus. Antimicrob Agents Chemother. 45, 1431-1437

13 Kerr, D. E., Plaut, K., Bramley, A. J., Williamson, C. M., Lax, A. J., Moore, K., Wells, K. D. and Wall, R. J. (2001) Lysostaphin expression in mammary glands confers protection against staphylococcal infection in transgenic mice. Nat Biotechnol. 19, 66-70

14 Kokai-Kun, J. F., Walsh, S. M., Chanturiya, T. and Mond, J. J. (2003) Lysostaphin cream eradicates Staphylococcus aureus nasal colonization in a cotton rat model. Antimicrob Agents Chemother. 47, 1589-1597

$15 \mathrm{Wu}$, J. A., Kusuma, C., Mond, J. J. and Kokai-Kun, J. F. (2003) Lysostaphin disrupts Staphylococcus aureus and Staphylococcus epidermidis biofilms on artificial surfaces. Antimicrob Agents Chemother. 47, 3407-3414

16 Shah, A., Mond, J. and Walsh, S. (2004) Lysostaphin-coated catheters eradicate Staphylococccus aureus challenge and block surface colonization. Antimicrob Agents Chemother. 48, 2704-2707

17 Wall, R. J., Powell, A. M., Paape, M. J., Kerr, D. E., Bannerman, D. D., Pursel, V. G., Wells, K. D., Talbot, N. and Hawk, H. W. (2005) Genetically enhanced cows resist intramammary Staphylococcus aureus infection. Nat Biotechnol. 23, 445-451

18 Grundling, A. and Schneewind, O. (2006) Cross-linked peptidoglycan mediates lysostaphin binding to the cell wall envelope of Staphylococcus aureus. J Bacteriol. 188, 2463-2472

19 Sugai, M., Fujiwara, T., Akiyama, T., Ohara, M., Komatsuzawa, H., Inoue, S. and Suginaka, H. (1997) Purification and molecular characterization of glycylglycine endopeptidase produced by Staphylococcus capitis EPK1. J Bacteriol. 179, 1193-1202

20 Ramadurai, L. and Jayaswal, R. K. (1997) Molecular cloning, sequencing, and expression of lytM, a unique autolytic gene of Staphylococcus aureus. J Bacteriol. 179, 3625-3631

21 Simmonds, R. S., Simpson, W. J. and Tagg, J. R. (1997) Cloning and sequence analysis of zooA, a Streptococcus zooepidemicus gene encoding a bacteriocin-like inhibitory substance having a domain structure similar to that of lysostaphin. Gene. 189, 255-261

22 Hickey, R. M., Twomey, D. P., Ross, R. P. and Hill, C. (2003) Production of enterolysin A by a raw milk enterococcal isolate exhibiting multiple virulence factors. Microbiol. 149, 655-664

23 Beukes, M., Bierbaum, G., Sahl, H. G. and Hastings, J. W. (2000) Purification and partial characterization of a murein hydrolase, millericin B, produced by Streptococcus milleri NMSCC 061. Appl Environ Microbiol. 66, 23-28

24 Kline, S. A., de la Harpe, J. and Blackburn, P. (1994) A colorimetric microtiter plate assay for lysostaphin using a hexaglycine substrate. Anal Biochem. 217, 329-331

25 Zhou, R., Chen, S. and Recsei, P. (1988) A dye release assay for determination of lysostaphin activity. Anal Biochem. 171, 141-144

26 Odintsov, S. G., Sabala, I., Marcyjaniak, M. and Bochtler, M. (2004) Latent LytM at 1.3A resolution. J Mol Biol. 335, 775-785 
27 Warfield, R., Bardelang, P., Saunders, H., Chan, W. C., Penfold, C., James, R. and Thomas, N. R. (2006) Internally quenched peptides for the study of lysostaphin: An antimicrobial protease that kills Staphylococcus aureus. Org \& Biomol Chem. 4, 3626-3638

28 Sambrook, J., Fritsch, E. F. and Maniatis, T. (1989) Molecular Cloning: a Laboratory Manual. Cold Spring Harbor Laboratory., Cold Spring Harbor, NY

29 Szweda, P., Pladzyk, R., Kotlowski, R. and Kur, J. (2001) Cloning, Expression, and Purification of the Staphylococcus simulans Lysostaphin Using the Intein-Chitin-Binding Domain (CBD) System. Protein Expr Purif. 22, 467-471

30 Lai, A. C., Tran, S. and Simmonds, R. S. (2002) Functional characterization of domains found within a lytic enzyme produced by Streptococcus equi subsp. zooepidemicus. FEMS Microbiol Lett. 215, 133-138

31 Garinot-Schneider, C., Penfold, C. N., Moore, G. R., Kleanthous, C. and James, R. (1997) Identification of residues in the putative TolA box which are essential for the toxicity of the endonuclease toxin colicin E9. Microbiol. 143, 2931-2938

32 Sarkar, G. and Sommer, S. S. (1990) The Megaprimer Method of Site-Directed Mutagenesis. Biotechniques. 8, 404-407

33 Gill, S. C. and von Hippel, P. H. (1989) Calculation of protein extinction coefficients from amino acid sequence data. Anal Biochem. 182, 319-326

34 Kessler, E., Safrin, M., Olson, J. C. and Ohman, D. E. (1993) Secreted LasA of Pseudomonas aeruginosa is a staphylolytic protease. J Biol Chem. 268, 7503-7508

35 Cox, R. A., Conquest, C., Mallaghan, C. and Marples, R. R. (1995) A major outbreak of methicillin-resistant Staphylococcus aureus caused by a new phage-type (EMRSA-16). The J Hosp infect. 29, 87-106

36 Forster, T. (1948) Intermolecular energy transfer and fluorescence. Annals Physik. 2, 55-75

37 Kraynov, V. S., Chamberlain, C., Bokoch, G. M., Schwartz, M. A., Slabaugh, S. and Hahn, K. M. (2000) Localized Rac activation dynamics visualized in living cells. Science. 290, 333337

38 Collins, E. S., Whittaker, S. B., Tozawa, K., MacDonald, C., Boetzel, R., Penfold, C. N., Reilly, A., Clayden, N. J., Osborne, M. J., Hemmings, A. M., Kleanthous, C., James, R. and Moore, G. R. (2002) Structural dynamics of the membrane translocation domain of colicin E9 and its interaction with TolB. J Mol Biol. 318, 787-804

39 Liu, Y., Kati, W., Chen, C. M., Tripathi, R., Molla, A. and Kohlbrenner, W. (1999) Use of a fluorescence plate reader for measuring kinetic parameters with inner filter effect correction. Anal Biochem. 267, 331-335

40 Simmonds, R. S., Pearson, L., Kennedy, R. C. and Tagg, J. R. (1996) Mode of action of a lysostaphin-like bacteriolytic agent produced by Streptococcus zooepidemicus 4881. Appl Environ Microbiol. 62, 4536-4541

41 Firczuk, M., Mucha, A. and Bochtler, M. (2005) Crystal structures of active LytM. J Mol Biol. 354, 578-590

42 Sugai, M., Fujiwara, T., Ohta, K., Komatsuzawa, H., Ohara, M. and Suginaka, H. (1997) epr, which encodes glycylglycine endopeptidase resistance, is homologous to fem $A B$ and affects serine content of peptidoglycan cross bridges in Staphylococcus capitis and Staphylococcus aureus. J Bacteriol. 179, 4311-4318

43 DeHart, H. P., Heath, H. E., Heath, L. S., LeBlanc, P. A. and Sloan, G. L. (1995) The lysostaphin endopeptidase resistance gene (epr) specifies modification of peptidoglycan cross bridges in Staphylococcus simulans and Staphylococcus aureus. Appl Environ Microbiol. 61, $1475-1479$

44 Ehlert, K., Tschierske, M., Mori, C., Schroder, W. and Berger_Bachi, B. (2000) Site-specific serine incorporation by Lif and Epr into positions 3 and 5 of the Staphylococcal peptidoglycan interpeptide bridge. J Bacteriol. 182, 2635-2638

45 Tozawa, K., Macdonald, C. J., Penfold, C. N., James, R., Kleanthous, C., Clayden, N. J. and Moore, G. R. (2005) Clusters in an Intrinsically Disordered Protein Create a Protein-Binding Site: The TolB-Binding Region of Colicin E9. Biochemistry. 44, 11496-11507

46 Fujiwara, T., Aoki, S., Komatsuzawa, H., Nishida, T., Ohara, M., Suginaka, H. and Sugai, M. (2005) Mutation analysis of the histidine residues in the glycylglycine endopeptidase ALE-1. J Bacteriol. 187, 480-487 
47 Heath, L. S., Gargis, S. R., Smithberg, S. R., Johnson, H. P., Heath, H. E., Leblanc, P. A. and Sloan, G. L. (2005) Plasmid-specified FemABX-like immunity factor in Staphylococcus sciuri DD 4747. FEMS Microbiol Lett. 249, 227-231

\section{FIGURES}

Figure 1 Conserved residues in the endopeptidase domain of lysostaphin. (A) Alignment of the endopeptidase domain of lysostaphin and representative orthologues that include ALE-1, LytM and Zoocin A. The amino-acid residues in the mature lysostaphin sequence that are conserved in all the sequences are shown in bold in the alignment with their residue number shown at the top of the figure; (B) The biological activity of lysostaphin with the mutation H33A (a); D37A (b); Y81A (c); H83A (d); T107A (e); H114A (f); and H116A (g) were compared with lysostaphin (h) and an empty vector control (i) in a stab test; (C) Turbidity assay in which aliquots of a suspension of lyophilized EMRSA-16 cells were incubated with $1 \mu \mathrm{M}$ purified lysostaphin $(\mathbf{\bullet})$, lysostaphin mutant D37A $(\bullet)$, Y81A ( $\square)$, T107A $(\Delta)$, or a buffer alone control (O).

Figure 2 Cleavage of MV11 by lysostaphin. (A) The derivation of the components of MV11 is shown at the top of the figure with the lysostaphin cleavage site indicated by an arrow. The amino-acid sequence of the $N$-terminus of MV11 is shown below with the pentaglycine cleavage site residues highlighted in bold and the seven residues that link the colicin E9 sequence to GFP containing a $C$-terminal histidine tag $\left(\mathrm{H}_{6}\right)$ highlighted in italics. The residues that were introduced by site-directed mutagenesis in constructing MV11 are underlined and the original residues at these positions in colicin E9 are shown below the MV11 sequence. (B) The MV11 protein substrate labelled with Alexa Fluor 546 (MV11F) was incubated with buffer (lane 1); endopeptidase domain (lane 2) and lysostaphin (lane 3); the unlabelled MV11 protein substrate was incubated with buffer (lane 4); endopeptidase domain (lane 5) and lysostaphin (lane 6), and all the digests were run on SDS-PAGE. The identity of the protein bands are indicated by the arrows to the right of the figure. Protein molecular weight standard $(2.5 \mu \mathrm{g})$ was run in lane $\mathrm{M}$.

Figure 3 FRET assay of recombinant lysostaphin with MV11. (A) Emission spectra of 500nM MV11 (dotted line) and MV11F (solid line). The constructs were excited at $475 \mathrm{~nm}$ and fluorescence emission recorded between 490-650nm. The excitation and emission slit-width were 5 and $10 \mathrm{~nm}$ respectively. (B) Increase in fluorescence at $\lambda_{508} \mathrm{~nm}$ over time (excitation at $\left.\lambda_{475} \mathrm{~nm}\right)$. MV11F $(1 \mu \mathrm{M})$ was incubated with $200 \mathrm{nM}$ of full length lysostaphin $(\boldsymbol{\Delta})$, its endopeptidase domain $(\bullet)$, the T107A $(\bullet)$ and the H114A (x) mutants of lysostaphin. The first five minutes of the cleavage reaction are shown.

Figure 4 Cleavage of MV11-S1 to MV11-S5 monitored by SDS-PAGE. The biological substrates as indicated at the top of the figure were incubated without $(-)$ and with endopeptidase $(+\mathrm{E})$, or lysostaphin $(+\mathrm{L})$ in the left gel, and without $(-)$ and with endopeptidase $(+)$ in the right gel. $2.5 \mathrm{mg}$ of Protein molecular weight standard $(\mathrm{M})$ and the endopeptidase domain (E) or lysostaphin (L) were run as controls.

Figure 5 Competition FRET assay of recombinant endopeptidase with MV11F. Increase in fluorescence at $\lambda 508 \mathrm{~nm}$ over time (excitation at $\lambda 475 \mathrm{~nm})$. MV11F $(1 \mu \mathrm{M})$ was incubated with $1 \mu \mathrm{M}$ of endopeptidase ( $\bullet$, with $1 \mu \mathrm{M}$ of endopeptidase and $40 \mathrm{mM}$ triglycine $(\mathbf{a})$, with $1 \mu \mathrm{M}$ of endopeptidase and $160 \mu \mathrm{M}$ of decoy peptide exposing a GGGGG $(\boldsymbol{\Delta})$, or a GGSGG $(\bullet)$ or a AASAA site (x) . 
Table 1 The effect of serine residues on cleavage of MV11

\begin{tabular}{|l|l|l|l|l|l|l|l|}
\hline & \multicolumn{4}{|c|}{ Predicted mass } & \multicolumn{2}{l|}{ Observed mass } \\
\hline Protein & Uncut & $\mathbf{1 - 2}$ cleavage & $\mathbf{2 - 3}$ cleavage & $\mathbf{3 - 4}$ cleavage & 4-5 cleavage & Lysostaphin & LytM \\
\hline MV11 & $33,680.9$ & $29,517.7$ & $\mathbf{2 9 , 4 4 2 . 7}$ & $29,386.1$ & $\underline{29,329.0}$ & $29,445.5$ & $29,327.1$ \\
\hline MV11-S1 & $33,711.5$ & $29,517.7$ & $29,442.7$ & $\mathbf{2 9 , 3 8 6 . 1}$ & $\mathbf{2 9 , 3 2 9 . 0}$ & $29,387.7$ & $29,328.4$ \\
\hline MV11-S2 & $33,711.5$ & $29,547.7$ & $29,442.7$ & $29,386.1$ & $\underline{\mathbf{2 9 , 3 2 9 . 0}}$ & $29,327.5$ & $29,328.6$ \\
\hline MV11-S3 & $\mathbf{3 3 , 7 1 1 . 5}$ & $29,548.1$ & $29,473.1$ & $29,386.1$ & $29,329.0$ & N.D & N.D \\
\hline MV11-S5 & $33,711.5$ & $29,548.1$ & $\underline{\mathbf{2 9 , 4 7 3 . 1}}$ & $29,416.1$ & $29,359.0$ & $29,474.4$ & $29,474.4$ \\
\hline
\end{tabular}

The predicted mass of the protein listed in the left hand column, without its $N$-terminal methionine residue, is shown in the second column. The predicted mass of the large C-terminal fragment of the listed protein, assuming cleavage between the glycine residues of the target sequence indicated, is shown in columns three to six of the table. The experimentally observed mass of the protein listed after incubation with lysostaphin or with LytM are shown in the last two columns. The predicted mass of the lysostaphin cleavage product that is consistent with the experimentally observed mass is indicated in bold. The predicted mass of the LytM cleavage product that is consistent with the experimentally observed mass is underlined. N.D. = not determined. 


lysostaphin
Ale-1
LytM
Zoocin
Actinobacillus pleuropneumoniae
Borrelia burgordferi
Bradyrhizobium japonicum
Clostridium perfingens
Enterococcus faecalis
Flavobacteria bacterium
Nitrobacter hamburgensis
Pasturella multocida
Phi3A-phage - S.aureus
Pseudomonas aeruginosa
Rhodopseudomonas palustris
Staphylococcus saprophyticus
Streptomyces avermitilis
Streptomyces tenjimariensis
YebA-E.coli
Yersinia pestis

$33 \quad 37$

8183

GTPVRAISDGKIVEAGWTNYG-----GGNEIGLVENDGVHRQWYMHLSK---FNVWVGDRVKAGQIIGWSGSTGYST-APHLF HYGVDFFMN-VGTPVRAISDGKIVEAGWTNYG-------GGNEIGLVENDGVHRQWYMHLSK---FNVFVGDRVKAGQI I GWSGSTGYST-APHLF HYGVDYAMP-ENSPVYSLTDGIVVQAGWSNYG------GGNQVTIKEANSNNYQWYMHNNR ---LTV HVGDAVP VITVAVANG HNGVDFGIP-TGTPI IAPSDGVVEHIAYQAKG-------AGRY IKIRHG-H-ITTVYMHLSK---TLVZVGQSVKKGERIALSGNTGAST-GPHLF

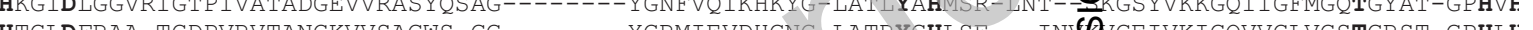
作 作 HRGIDLAVA-CGTIAAQDGRVVSAGDA-GSHTCIDFRAA-MGDPVRATANGKVVSASNACHCDDAA HYGD HYD HKVIAAP HTGLDFRAA HYGIDYHLP-EDIPIKAAADGKVTRTFDDDLG-----GKVIQIAESNGEYHQWYMHLNE---FKVEVGDDVKAGDTIALSGNTGEQTTGAHLF HTGVDFPV-TGISVRAVAGHVSAG--WGG-------SFGYQVVLRHADG-RYTQYAHLSA---ISUWAGQSVTADQRIGRSGSTGNST-GPHLF

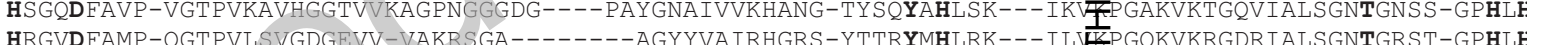
HRGD ***

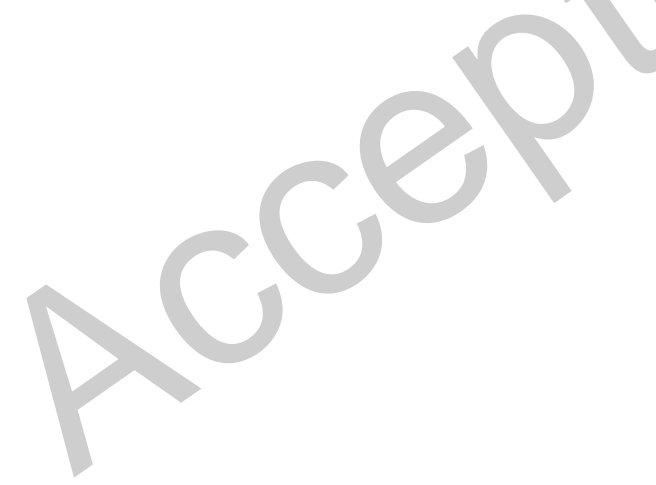

Licenced copy. Copying is not permitted, except with prior permission and as allowed by law. (C) 2008 The Authors Journal compilation (C) 2008 Portland Press Limited 

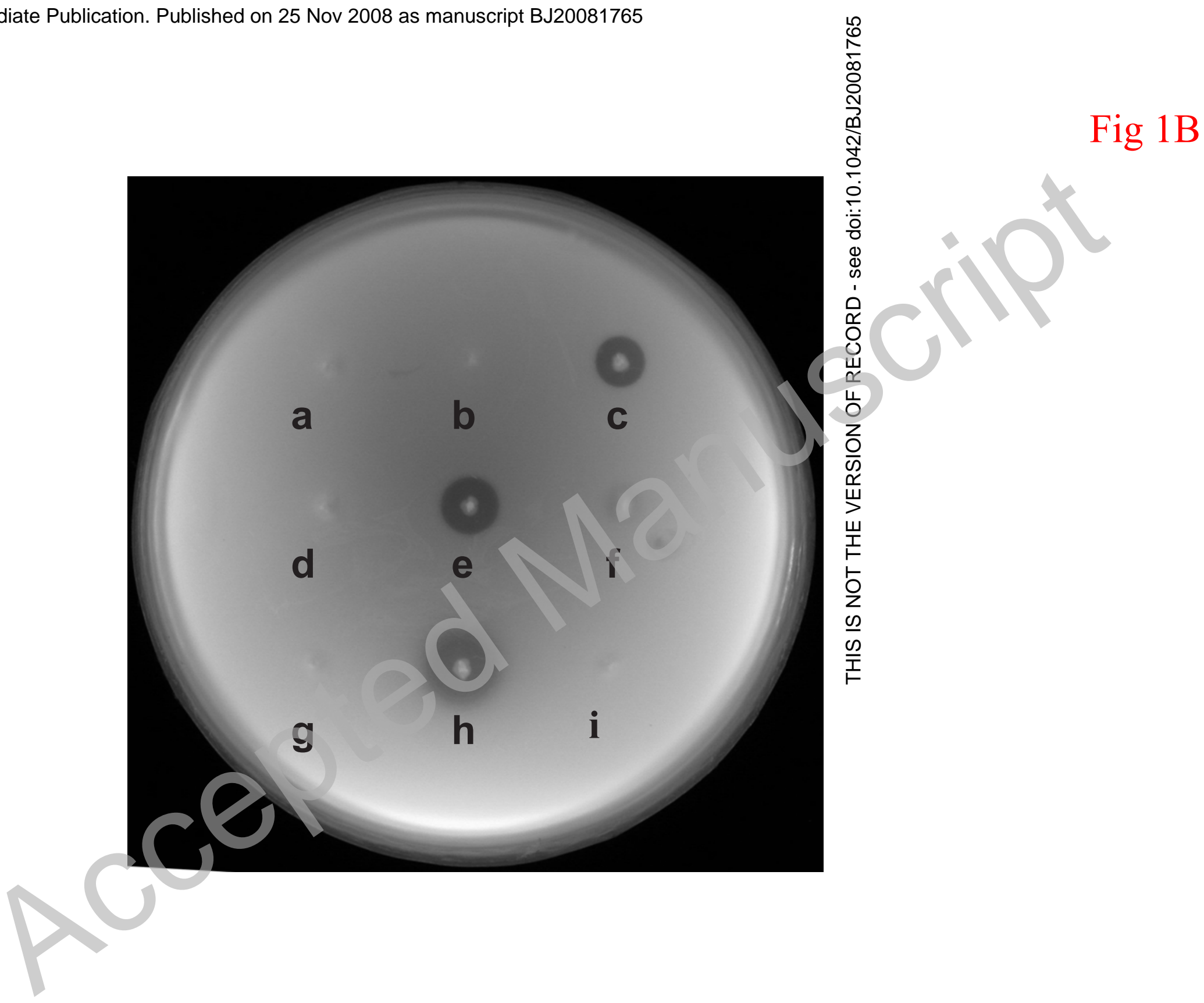


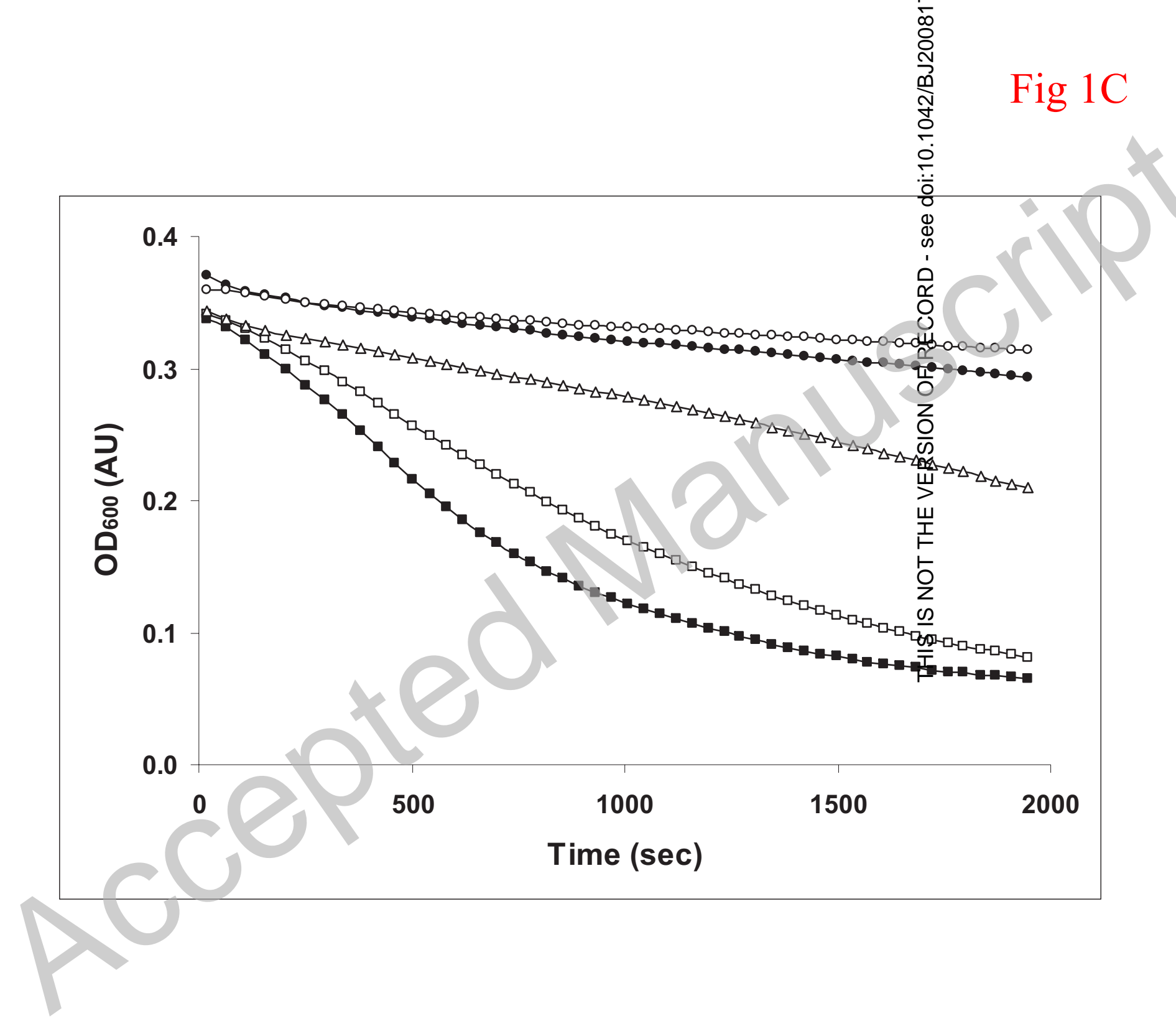


A

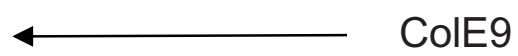

Cleavage site

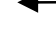

10

20

30

40

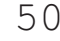

MSGGGGRGHNTGAHSTSGNINGGPTGIGVSGGASDGSGWSSENCPWGGGGGAAIHWG

$\mathrm{N}$

B

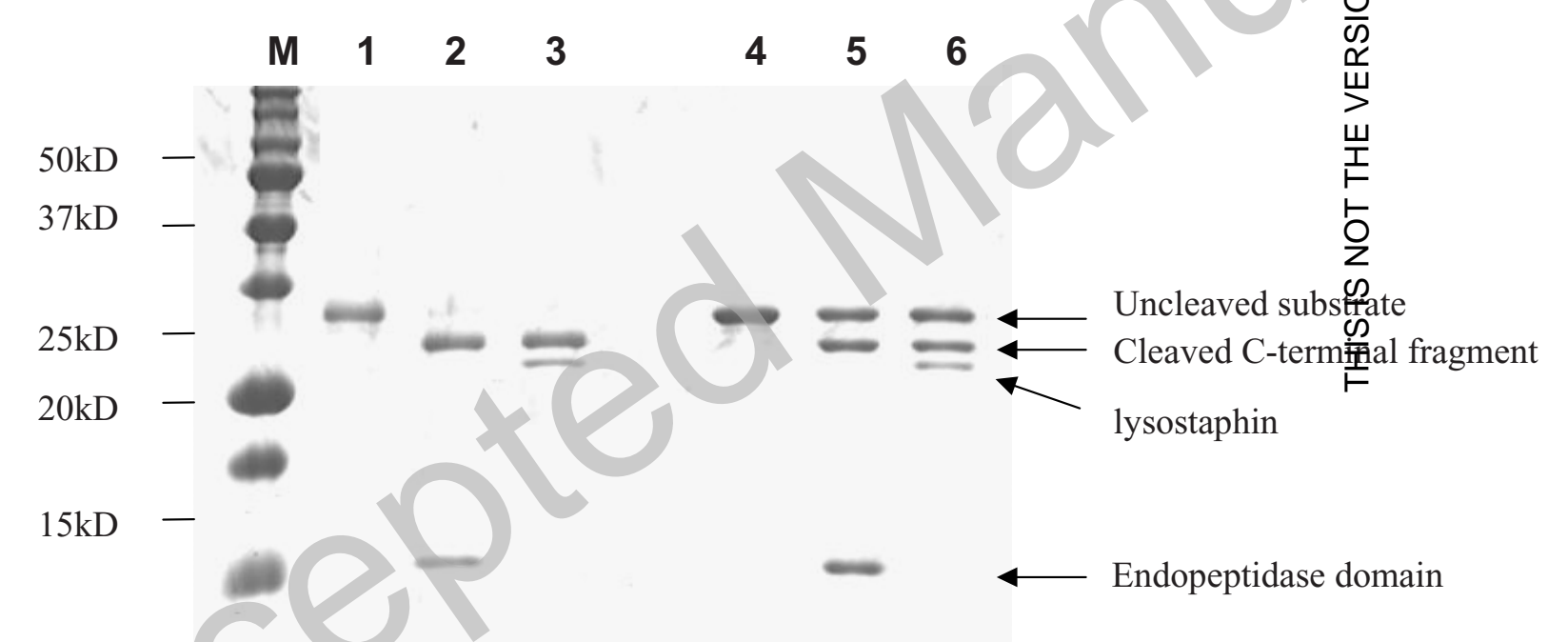

Licenced copy. Copying is not permitted, except with prior permission and as allowed by law.

(c) 2008 The Authors Journal compilation @ 2008 Portland Press Limited 


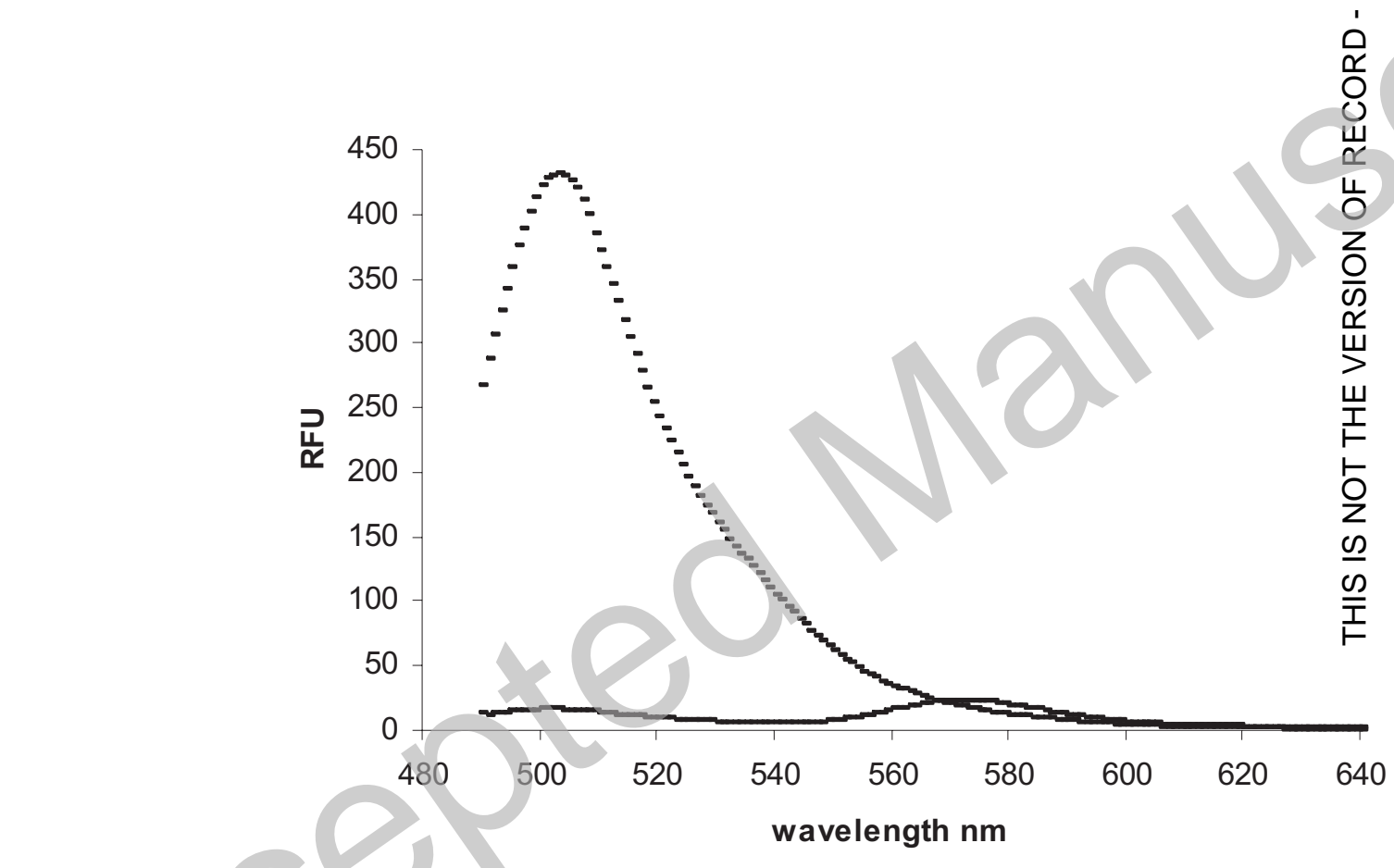

Fig 3A

Licenced copy. Copying is not permitted, except with prior permission and as allowed by law. () 2008 The Authors Journal compilation @ 2008 Portland Press Limited 
B) Biochemical Journal Immediate Publication. Published on 25 Nov 2008 as manuscript BJ20081765

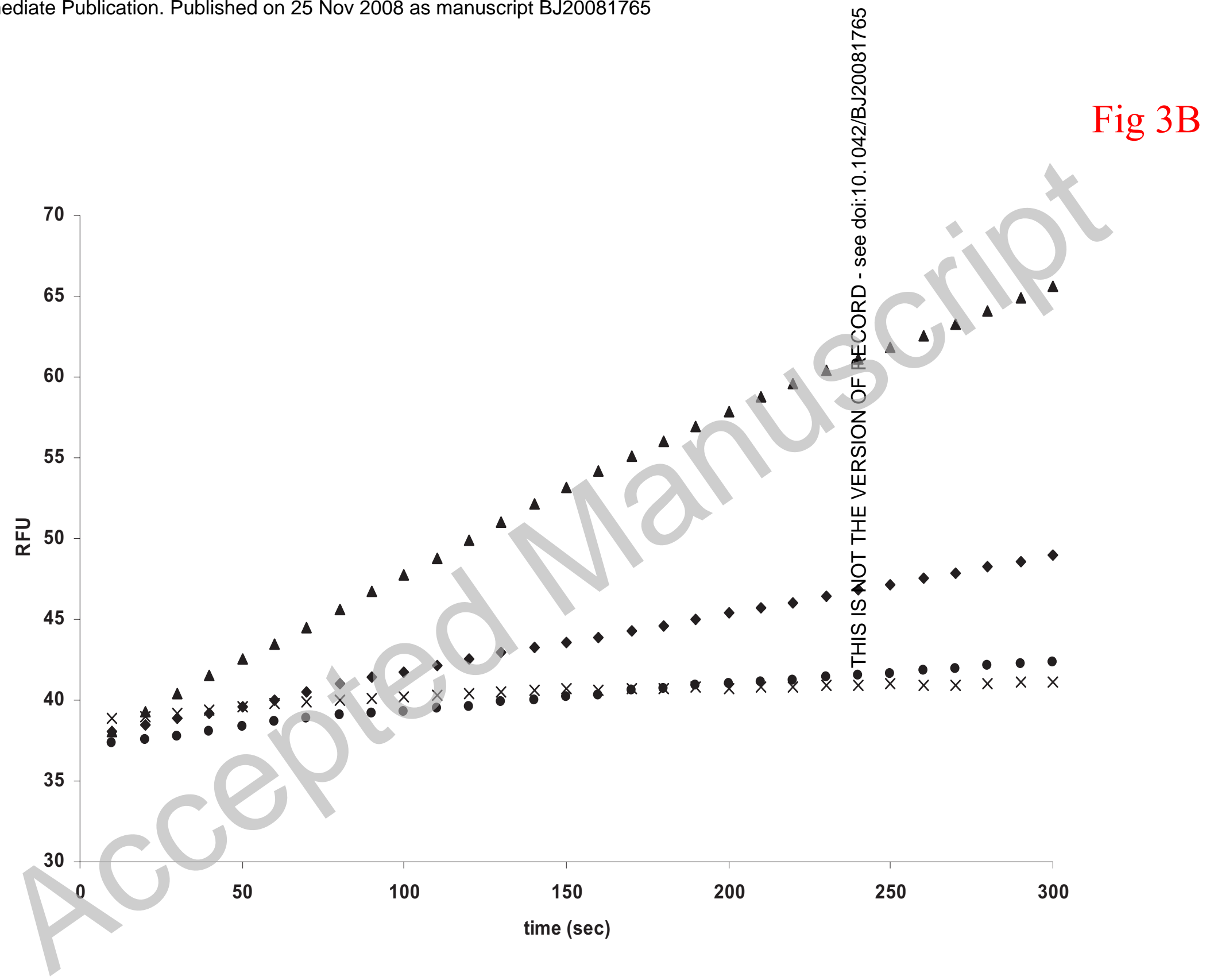



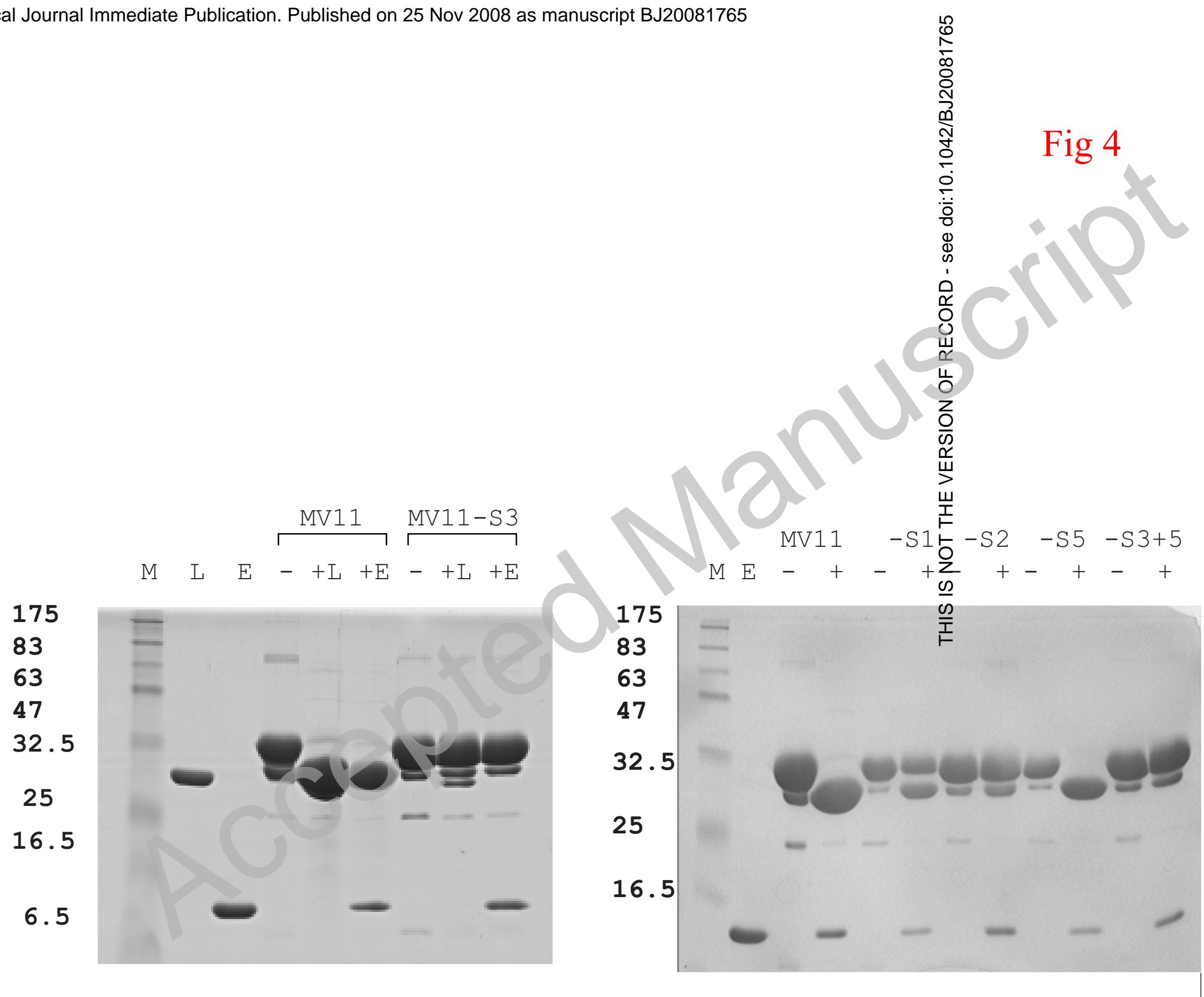

Licenced copy. Copying is not permitted, except with prior permission and as allowed by law. () 2008 The Authors Journal compilation @ 2008 Portland Press Limited 
B Biochemical Journal Immediate Publication. Published on 25 Nov 2008 as manuscript BJ20081765

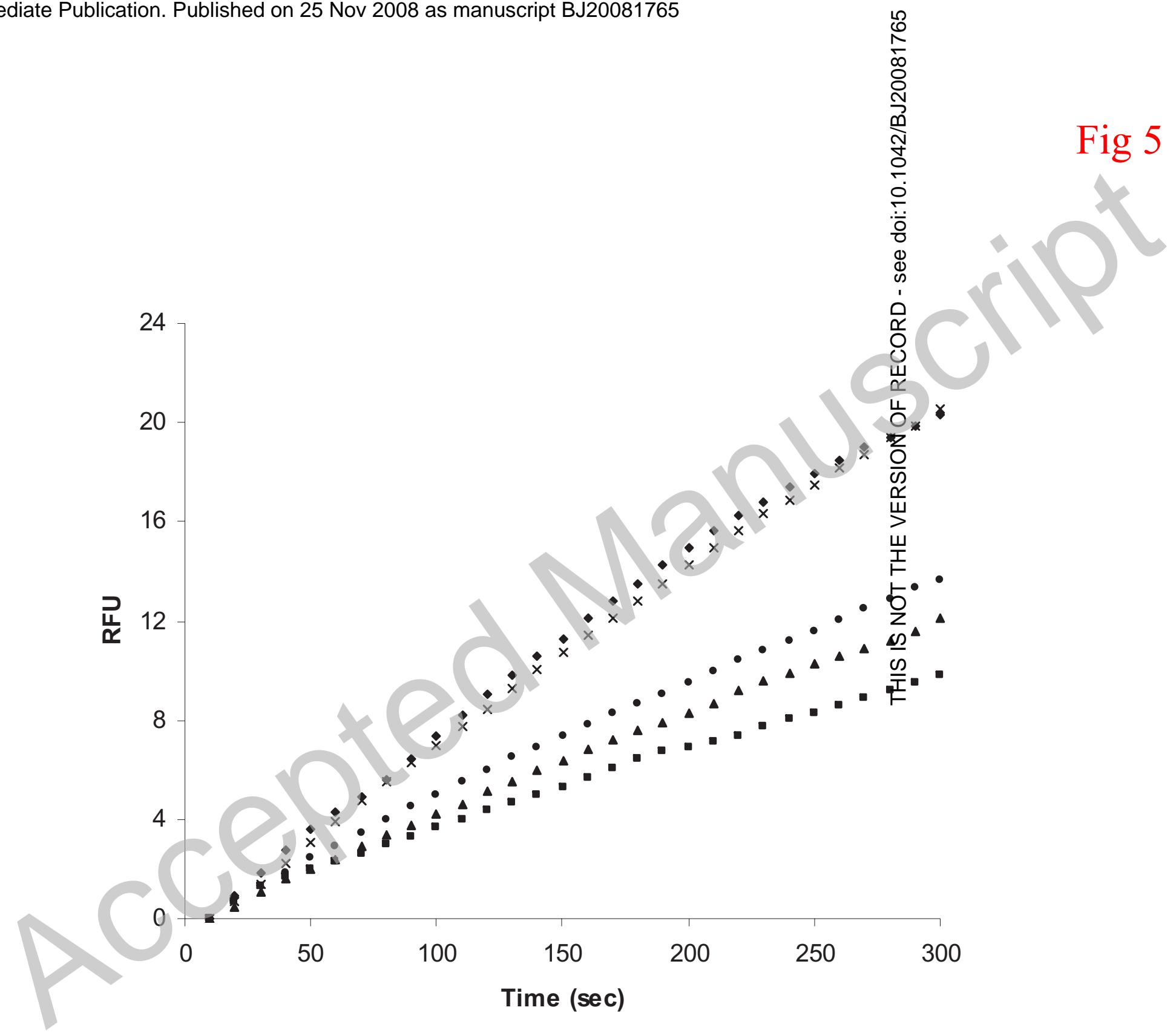

Licenced copy. Copying is not permitted, except with prior permission and as allowed by law.

(C) 2008 The Authors Journal compilation ( 2008 Portland Press Limited 